\title{
Academic Education in Complementary Medicine: a Tuscan Methodological Perspective
}

\author{
Gian Franco Gensini $i^{1,2,3}$ and Andrea A. Conti ${ }^{1,2,3}$ \\ ${ }^{1}$ Dipartimento di Area Critica Medico Chirurgica, Università degli Studi di Firenze, ${ }^{2}$ Fondazione Don Carlo Gnocchi, \\ IRCCS S. Maria agli Ulivi and ${ }^{3}$ Centro Italiano per la Medicina Basata sulle Prove, Firenze, Italy
}

\begin{abstract}
The implementation of complementary medicine (CM) involves a large number of persons in Italy, and in the nineties, the percentage of Italian citizens adopting the most frequent and relevant practices of $\mathrm{CM}$ almost doubled. Appropriate academic education in $\mathrm{CM}$ is an important and fascinating challenge for current didactic systems in the Italian University. Already in 2004, the Joint Italian Conference of the Deans of the Faculties of Medicine and of the Presidents of Medical Degree Courses released an official statement regarding the relationship between $\mathrm{CM}$ and health area degree courses. The main teaching objectives embedded in the institutional framework proposed by the Joint Italian Conference are now finding specific implementation modalities in the University of Florence. For many years, the Florence Medical School has had strong and fruitful contacts with institutional bodies in Tuscany and, together with these institutions, has established a continuous dialogue with the world of CM. This exchange has given rise to various teaching activities within the academic setting. With specific reference to the undergraduate curriculum in Medicine and Surgery, a methodological course regarding $\mathrm{CM}$ has been designed and conducted, with selective attention being given to the $\mathrm{CM}$ practices having an enhanced rate of supportive scientific evidence, such as herbal medicine and acupuncture. With regard to the postgraduate curriculum, a Master degree in Acupuncture and Traditional Chinese Medicine and a Master in Clinical Phytotherapy are already active in the University of Florence and are having a remarkable success among the attending health professionals. This high degree of satisfaction well documents the importance, need and feasibility of structured academic education in $\mathrm{CM}$ and, in particular, of a methodological didactics such as those currently implemented in the Florence Medical School.
\end{abstract}

Keywords: complementary medicine - evidence based medicine - clinical methodology medical education - history of medicine

\section{Background}

The implementation of complementary medicine (CM) involves a large number of persons in Italy and, according to official sources, is on the increase. In the nineties, the percentage of Italian citizens using the most frequent and relevant practices of $\mathrm{CM}$ almost doubled, and at the end

For reprints and correspondence: Andrea Alberto Conti, MD, MPH, $\mathrm{PhD}$, Dipartimento di Area Critica Medico Chirurgica, Università degli Studi di Firenze, Viale Morgagni 85, I-50134, Firenze, Italy. Tel: + 39055-4598011; Fax: + 39-055-4598947; E-mail: aa.conti@dac.unifi.it of that decade approximately 9 million people (that is about one Italian in six) stated they adopted, or had adopted, CM (1). Not only do Italian patients commonly use $\mathrm{CM}$, but Italian physicians also adopt and prescribe CM. Their number is estimated in more than 10000 doctors, according to recent data (2). This number is probably underestimated if other European countries are considered. Reliable sources indicate that in England, more than $20 \%$ of general practitioners use CM to treat their patients; this percentage increases to almost $50 \%$ in the Netherlands and to peaks of $80 \%$ in Germany (3).

This is an Open Access article distributed under the terms of the Creative Commons Attribution Non-Commercial License (http://creativecommons.org/ licenses/by-nc/2.0/uk/) which permits unrestricted non-commercial use, distribution, and reproduction in any medium, provided the original work is properly cited. 
The dimension of this social-health phenomenon is therefore significant and should not be underestimated by the different institutional bodies involved in its management, regulation and teaching. With regard to this last dimension, appropriate academic education in $\mathrm{CM}$ is an important and fascinating challenge for current didactic systems in the Italian University.

Already in 2004, the Joint Italian Conference of the Deans of the Faculties of Medicine and of the Presidents of Medical Degree Courses released an official statement (to which GF Gensini substantially contributed) regarding the relationship between CM and health area degree courses. This Joint Conference invited the Italian Faculties of Medicine to include the teaching of CM, if and when sustained by appropriate evidence, in specific didactic courses (e.g. Acupuncture in Anaesthesia and Resuscitation, Phytotherapy in Pharmacology and Toxicology). The Conference also suggested that the different Faculties of Medicine should critically assess those CM practices, the efficacy of which still had to be demonstrated and should dedicate the necessary educational efforts not only to single diseases, but also to individual subjects, in the wider context of the so-called 'medicine of the whole person' (4). The main teaching objectives embedded in the institutional framework proposed by the Joint Italian Conference are now finding specific implementation modalities in the different universities (5).

\section{Academic Teaching of Complementary Medicine}

For many years, the Florence Medical School has had strong and fruitful contacts with institutional bodies in Tuscany (the region where Florence is located), such as the Councillorship in charge of the Municipal Health Services and the Florentine Provincial College of Physicians. Together with these institutions, the Faculty of Medicine of the University of Florence has established a continuous dialogue with the world of CM. This exchange has given rise to various teaching activities within the academic setting (6).

The university didactic approach towards $\mathrm{CM}$ requires specific methodological competence, as interpreted in the Florence Medical School. CM education in the University of Florence is, in fact, shifting from a traditional model, centered on the transmission of information and data, to a more modern and effective paradigm, privileging the sharing of knowledge and the methodological development of critical abilities (7). The Medical School students, who in a few years' time will be the future general practitioners of the Italian health scenario, not only have to have knowledge of the best current evidence regarding $\mathrm{CM}$ practices, and in particular those that are 'better evidence-based' (such as acupuncture and phytotherapy), but also, and more importantly, have to master the methodological competence for life-long learning (8).

The broad area of CM requires the in-depth attainment of such abilities, since many of the practices it includes are undergoing rapid transformation and data on them are being published more and more often in the international literature (9). The physicians of the near future must therefore be capable of critically assessing new incoming evidence in a continuous, independent and self-directed educational environment (10).

The epidemiological dimension of $\mathrm{CM}$ practices in Italy, as in other countries, points to the need for the elaboration of appropriate evaluation skills in medical students, as indicated by the Italian Joint Academic Conference mentioned earlier. University education in the $\mathrm{CM}$ area in Florence is therefore selectively evidencebased, if and when evidence is available, and clinically and epidemiologically based when evidence is controversial, scanty or absent.

In a perspective of evidence-based $\mathrm{CM}$, the appropriate consideration of the fundamental dimensions of the effectiveness, safety, tolerability and easiness of use of $\mathrm{CM}$ does not exhaust the teaching and learning tasks. It is well known that, besides 'knowing' and 'knowing how to do', the dimension of 'knowing how to be' is essential in reaching a full concordance between physicians and patients. Current data indicate that one of the main merits of $\mathrm{CM}$ practices is that of dedicating, on the part of the operators in the field, great attention and much time to patients (11). This awareness must constitute a major stimulus for academic educative environments, so as to empower and to address in a more targeted fashion, the relational and communicative capacities of students (Fig. 1).

The 'medicine of the whole person' approach cannot do without appropriate knowing, knowing how to do and knowing how to be, in the context of a dynamic and more comprehensive physician-patient relationship. Italian surveys document that, in many cases, currently active physicians neither have sufficient knowledge of $\mathrm{CM}$ practices, nor specifically ask patients about their real or potential use of CM remedies (2). Together

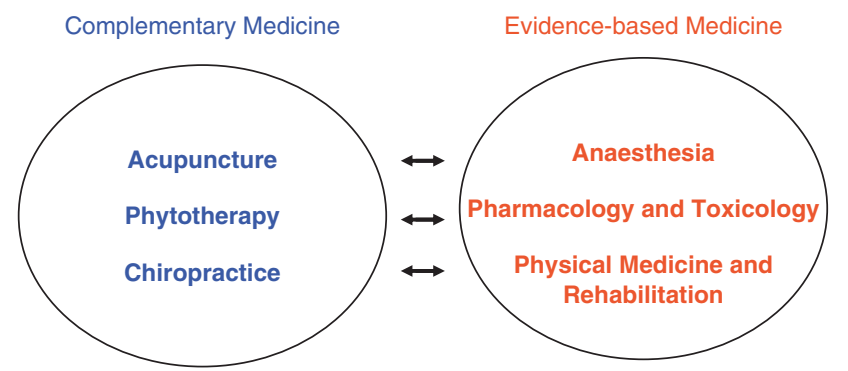

Figure 1. Evidence-based CM: a model of interaction. Modified from (4). 
with the evidence-based medicine approach, therefore, tailored history-taking procedures, focussing on the adoption of $\mathrm{CM}$ remedies on the part of the patients, have been developed in Florence, to teach for the first time a modern, comprehensive and updated clinical approach to undergraduate students, and to reinforce it when they have already graduated. Indeed, the methodological educational effort of the Florence Medical School in the area of CM is addressed towards multiple levels of health education, thus including not only the undergraduate but also the postgraduate curriculum.

\section{Florence Medical School Methodological Education in $\mathrm{CM}$}

With regard to the postgraduate curriculum, a Master degree in Acupuncture and Traditional Chinese Medicine and a Master degree in Clinical Phytotherapy are already active in the Florence Medical School and are having a remarkable success among the attending health professionals. The Master in Acupuncture and Traditional Chinese Medicine was activated in January 2006 by the University of Florence in collaboration with the Beijing University of Chinese Medicine (China). This Master includes informative and formative features and both Italian and Chinese University professors are involved in its integrated teaching (12). The synergic and collaborative dimensions of this Master are also evidenced by the presence of numerous skilled acupunctors and phytotherapists belonging to organizations constituting the Italian Federation of Acupuncture Societies.

The general structure of this cooperative Master provides for Italian University teaching in the context of evidence-based and frontal theoretical didactics (including the teaching of the history of Traditional Chinese Medicine and of the evidence-based history of $\mathrm{CM}$, in which AA Conti is involved), while Italian nonUniversity and Chinese teachers and tutors deal with the clinical section of the Master and follow the practical training of the students, including a residential clinical stage in the University of Beijing (12).

An evolution of this Master has already taken place, since, from 2007, teaching courses regarding advanced methodological didactics (evidence-based integrated therapy) and specialist topics of Chinese Traditional Medicine have been implemented. In effect, the particular characteristics of the Florentine Master include the full integration of international specific competences, the flexibility of methodological education and the overall collaborative attitude that reflects itself in established links with other teaching and research structures of the Florence Medical School.

In the School of Medicine of Florence, a Centre for Higher Education and Translational Research in General Practice has been active since 2005, to promote and disseminate the teaching of general practice in the setting of the Faculty of Medicine of Florence, by means of educational activities not only within the medicine degree course, but also in speciality schools and courses (13). Taking into account that in the Italian region of Tuscany, almost $25 \%$ of the whole population uses CM (it should also be noted that in Tuscany there is a large Chinese community), compared to the (approximately) 15\% representing the Italian national average, the clinical and methodological knowledge of CM practices becomes fundamental for general practitioners. Recent regional surveys indicate that in Tuscany, the use of CM is on the increase, and therefore future general practitioners will need more and more, in the clinical arena, to tackle and, on methodological grounds, to master a number of the most adopted CM practices (14). The connections between postgraduate academic education, such as that included in Florentine Masters, and the Florence Medical School Centre for Higher Education and Translational Research in General Practice, are precisely targeted to these aims. This Centre of the University of Florence has in fact elaborated and disseminated teaching and research initiatives in the context of cure modeling and of primary care, and its already strong links with undergraduate education are planned to be further empowered with specific regard to CM.

With selective reference to the undergraduate curriculum in Medicine and Surgery, a methodological course regarding $\mathrm{CM}$ has been designed and conducted, with close attention being given to the CM practices having a higher degree of supportive scientific evidence, including herbal medicine and acupuncture. As recommended by the Joint Italian Conference of the Deans of the Faculties of Medicine and of the Presidents of Medical Degree Courses, mentioned earlier, other CM practices are being evaluated on methodological grounds in the Florentine course, and the general approach to CM teaching in the undergraduate curriculum is highly articulated and integrated, in harmony with the articulation and synergic integration that currently appear to be the best ways of guaranteeing the preparation and satisfaction of the students.

The key terms of undergraduate academic education in the Florence Medical School may be indicated as follows: theoretical basis, best evidence, clinical-practical training, physician-patient relationship, therapeutic application, guidelines. A brief description of their interpretation in Florence is synthetically given here.

A presentation and discussion of the different theoretical scenarios of the various CM practices is furnished since, without a real comprehension of 'non-standard' medical approaches, it would become difficult to understand the preferences and values of the many patients who use them. The full comprehension of the theoretical bases of CM must not impede the critical appraisal of the evidence base of its practices. 
Evidence-based medicine is the systematic approach adopted to collocate correctly the benefits and risks of CM practices in the Western scientific panorama, and to boost the relevant clinical-practical training foreseen in particular for postgraduate students (as in the Florentine Master in Acupuncture and Traditional Chinese Medicine).

With regard to undergraduate students, the clinical consequences of the evidence-based approach must be and, in the Florentine academic environment are, clearly presented in terms of advantages and limits. Only a real knowledge and mastering of these advantages and limits on the part of health operators can lead to a modern and open relationship between physicians and patients.

The fundamental elements of relational competence can be taught and learned, and undergraduate students have to learn them during their degree course, with special attention to the use of $\mathrm{CM}$ by patients, who, if not specifically asked about that feature, not infrequently do not refer its use.

This potential, and often actual, lack of reporting may constitute a notable damage for the patients themselves, and therefore selective attention is dedicated, in the Florentine academic teaching of $\mathrm{CM}$, to the therapeutic applications of $\mathrm{CM}$ and to the interactions between complementary treatments and standard use drugs.

The familiarization with available guidelines on these and other major clinical topics, to complete the key elements of CM academic education in the Tuscan context, constitutes a methodological task relevant for every student (15).

\section{Conclusions and Perspectives}

In conclusion, the Florentine academic educational model and methodological perspective regarding $\mathrm{CM}$ foresees two major pillars: the constant monitoring of the scientific base of what is proposed by CM practices and the complete transparency of formative pathways in the academic environment. Both these pillars are necessary but not sufficient by themselves, and therefore the optimal integration of human, managerial and organizational resources is mandatory for the design of a university curriculum that really and effectively embeds the correct teaching of $\mathrm{CM}$. The notable confidence in, and the remarkable dimension of the employment of $\mathrm{CM}$ in the Italian population, and in the Tuscan area in particular, warrants the dedicating of adequate clinical, epidemiological and methodological attention to $\mathrm{CM}$ in the academic setting. It is precisely to further these ends that the Florence Medical School has set up, and is currently perfecting, a comprehensive medical 'toolbox' for the physicians of the near future, namely, undergraduate and postgraduate students.

\section{Acknowledgement}

The authors would like to thank Prof. Luisa Camaiora, BA, MPhil., for her correction of the English.

\section{References}

1. Easthope G, Tranter B, Gill G. General practitioners' attitudes toward complementary therapies. Soc Sci Med 2000;51:1555-61.

2. FNOMCeO. Medicine Non Convenzionali. Deliberazioni del Consiglio Nazionale 18 maggio 2002.

3. Varga O, Marton S, Molnar P. Status of complementary and alternative medicine in European Medical Schools. Forsch Komplementarmed 2006;13:41-5.

4. Medicine Complementari e/o Alternative (CAM) e Corsi di Laurea dell'Area Sanitaria (in particolare Corso di Laurea Specialistica in Medicina e Chirurgia). Riflessioni scaturite dalla Conferenza Congiunta dei Presidi e dei Presidenti dei CC.CC.dd.LL. in Medicina e Chirurgia, Alghero, 2 maggio 2004. Contributi particolari di Alessandro Lechi e di Italo Vantini, di Gian Franco Gensini, di Antonio Conti e di Luigi Frati.

5. Gensini GF, Lippi D, Conti A, Conti AA. Complementary and alternative medicine: an academic view. Med Princ Pract 2005;14:441-3.

6. Gensini GF, Conti A, Lippi D, Conti AA. Full integration of teaching 'Medical Humanities' in the medical curriculum: the challenge of the Florence Medical School. Med Princ Pract 2005; 14:64-5.

7. Gensini GF, Conti AA, Conti A. The concept of 'Context' in health care: historical perspective and current views. Clin Ter 2006;157:273-6.

8. Gensini GF, Conti AA, Lippi D, Conti A. The past and present history of the term 'Quality' in medicine. Rec Prog Med 2004;95:226-30.

9. Hill FJ. Complementary and alternative medicine: the next generation of health promotion? Health Promot Int 2003;18:265-72.

10. Conti AA, Galanti C, Gensini GF. Is evidence based medicine really a craze? A methodological comment from the Italian Centre for Evidence Based Medicine. Ital Heart J Suppl 2000;1:1192-5.

11. Owen D, Lewith GT. Teaching integrated care: CAM familiarisation courses. Med J Aust 2004;181:276-8.

12. Vannacci A, Giovanardi CM, Geppetti P, Mugelli A, Gensini GF. Modelli di integrazione a livello di didattica universitaria. In: Giarelli G, Roberti di Sarsina P, Silvestrini B (eds). Le Medicine Non Convenzionali in Italia. Milano, Italy: Franco Angeli Sanità, 2007, 205-17.

13. Gensini GF, Panti A, Conti AA. The Florence Medical School Centre for Higher Education and Translational Research in General Practice. Med Educ 2007;41:504.

14. Ordine dei Medici Chirurghi e degli Odontoiatri della Provincia di Firenze. Deliberazione n. 45 del 18/4/2000. Linee guida per la presenza dei medici, degli odontoiatri e delle strutture sanitarie sulla rete Internet.

15. Rampes H, Sharples F, Fisher P. Complementary medicine in the medical curriculum. J R Soc Med 1997;90:357. 


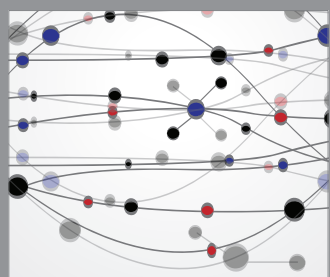

The Scientific World Journal
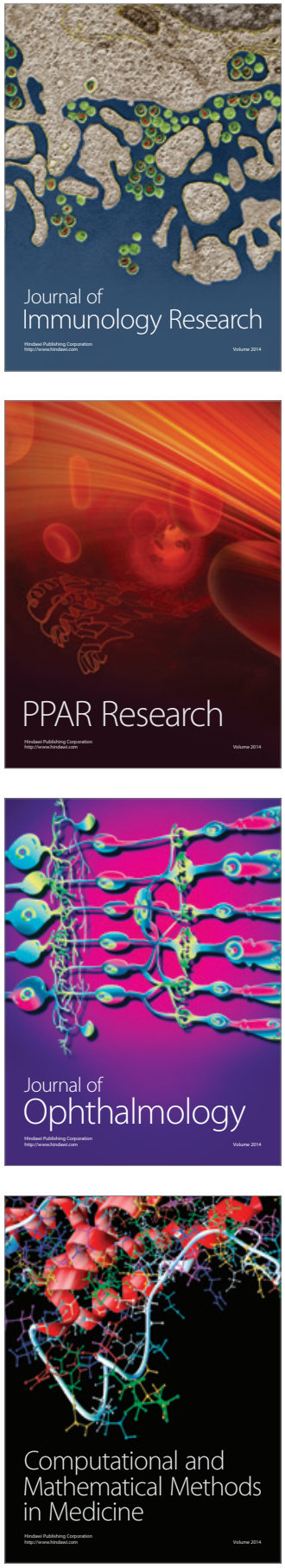

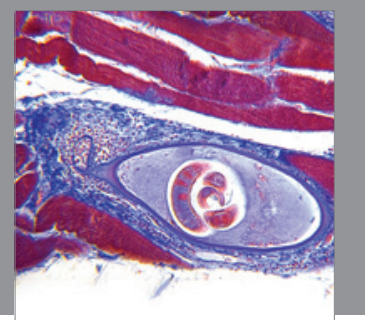

Gastroenterology

Research and Practice
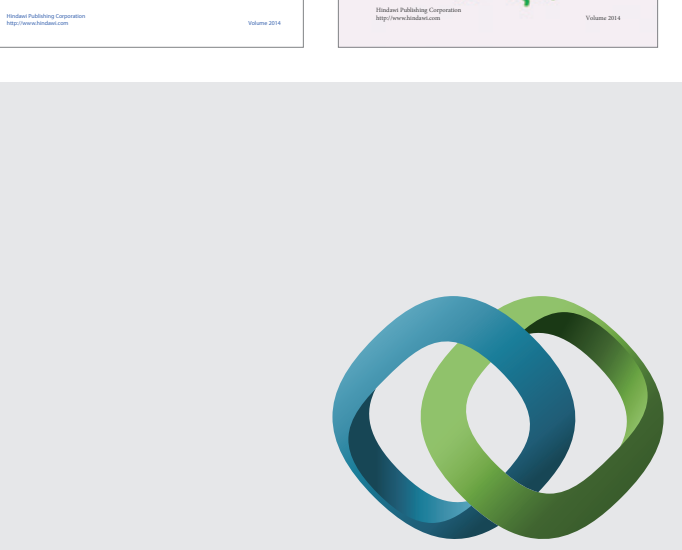

\section{Hindawi}

Submit your manuscripts at

http://www.hindawi.com
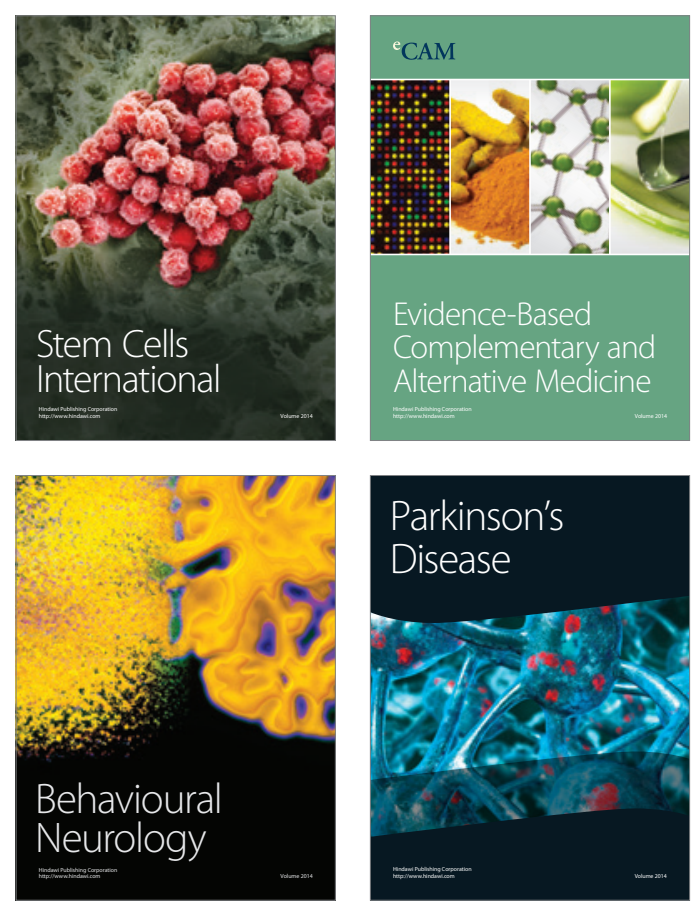

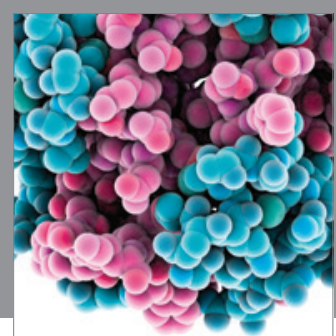

Journal of
Diabetes Research

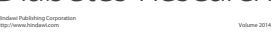

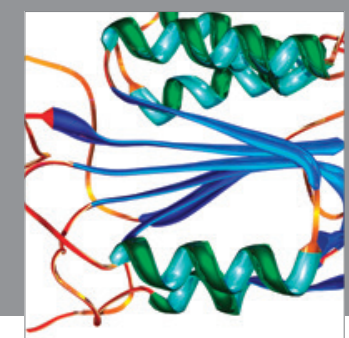

Disease Markers
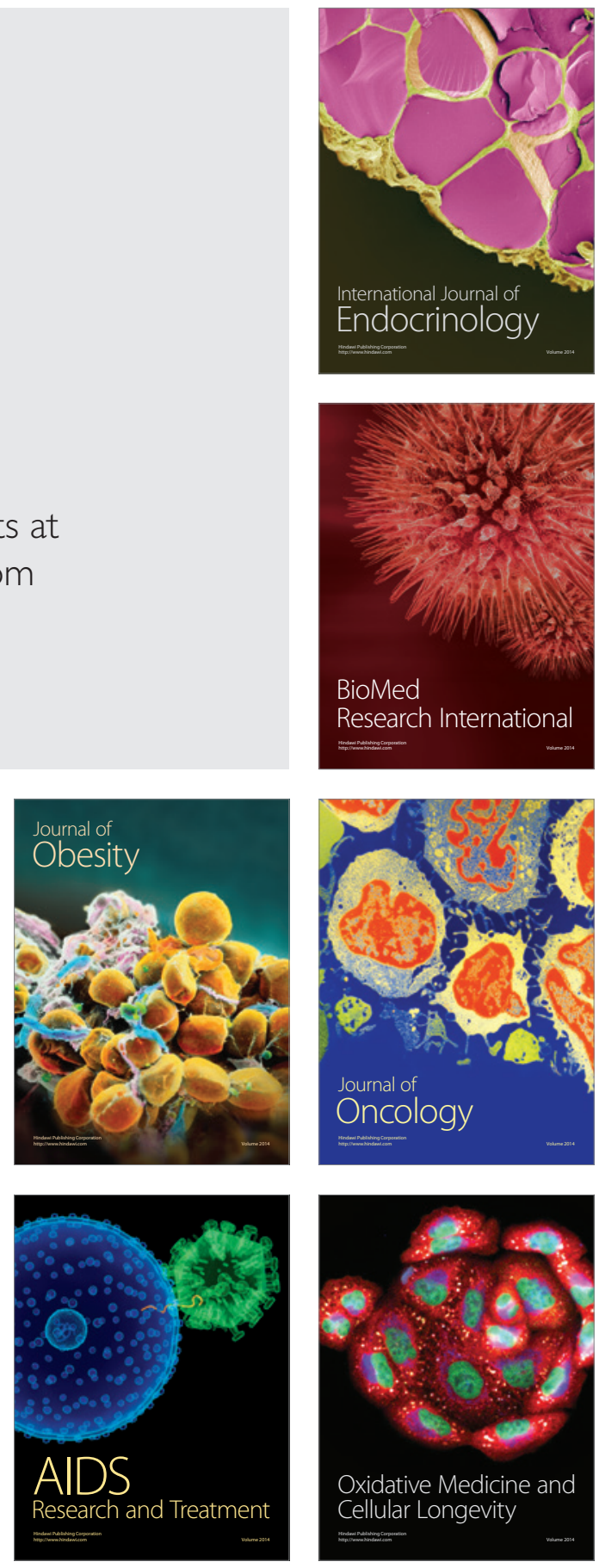